\title{
The Influence of a Goalkeeper as an Outfield Player on Defensive Subsystems in Futsal
}

\author{
Umberto C. Corrêa1, Keith Davids'², Silvia L. Silva', Renata A. Denardi', Go Tani1 \\ ${ }^{1}$ Escola de Educação Física e Esporte, Universidade de São Paulo, São Paulo, Brazil \\ ${ }^{2}$ Centre for Sports Engineering Research, Sheffield Hallam University, Sheffield, UK \\ Email: umbertoc@usp.br
}

Received 2 March 2014; revised 2 April 2014; accepted 9 April 2014

Copyright (C) 2014 by authors and Scientific Research Publishing Inc.

This work is licensed under the Creative Commons Attribution International License (CC BY).

http://creativecommons.org/licenses/by/4.0/

(c) (i) Open Access

\begin{abstract}
The aim of this study was to investigate the influence of the goalkeeper as an outfield player on defensive subsystems in the team sport of futsal. For this purpose, all sequences of play involving the goalkeeper $(n=65)$, and the sequences without a goalkeeper (controls) $(n=11)$, were selected from digital video footage of a futsal competition, and analysed using TACTO software. The defensive area, attacker-defender distance, and interception distance were used to examine players' coordination tendencies as a team in completion of successful and unsuccessful passes and shots. Results showed that each team reduced its defensive area as well as its variability in situations where the goalkeeper acted as an outfield player. This finding implies that it was an effective defensive strategy because it led to emergence of more unsuccessful passes. It was also observed that the goalkeeper acting as an outfield player was an effective strategy for attacking in terms of increasing shots at goal.
\end{abstract}

\section{Keywords}

Ecological Dynamic, Interpersonal Coordination, Team Sport, Decision-Making, Futsal

\section{Introduction}

One of the most intriguing phenomena in social systems concerns how the presence and actions of one performer directly affects the perceptions and actions of another (Marsh, Richardson, Baron, \& Schmidt, 2006). This is certainly the case in team sports, in which a player's actions have shown to influence the actions of their teammates and opponents, and vice versa (Corrêa, Alegre, Freudenheim, Santos, \& Tani, 2012). In fact, team sports are social systems in nature because, as in any collective, individuals interact in space and time, constrained by rules, and undertaking distinctive functions. 
Consideration of the interaction phenomenon is the basis for understanding behaviours in team sports (Schmidt, O’Brien, \& Sysko, 1999). Due to the number of players and their modes of interaction, team sports can also be characterized as complex social systems (Corrêa, Alegre et al., 2012). Indeed, complexity has also been considered as an important aspect of understanding interactions between players in team sports, since complex social systems tend to display emergent properties (Davids, Araújo, \& Shuttleworth, 2005; Garganta \& Cunha e Silva, 2000; Gréhaigne, Bouthier, \& David, 1997; McGarry, 2009; McGarry, Anderson, Wallace, Hughes, \& Franks, 2002). Studies have revealed that the patterns observed over the course of a game are consequence of continuous interpersonal interactions between players, rather than due to the isolated actions of individual players.

In team sports, players mainly interact in two ways: 1) cooperating with each other, which results in the emergence of stable team patterns; and 2), as a team, players interact through opposing another team (McGarry, 2009; McGarry \& Franks, 1996; McGarry et al., 2002). These kinds of interactions reflect the "interpersonal coordination tendencies" of team games players (Passos, Araújo, Davids, Gouveia, Milho, \& Serpa, 2009; Passos, Araújo, Davids, Gouveia, Serpa, Milho, \& Fonseca, 2009). Cooperative and oppositional interpersonal coordination modes result in a dynamic process of pattern-formation within a team game.

Recently, the conception of hierarchically organized systems has been incorporated into studies of team sports (Corrêa, Alegre et al., 2012; Gréhaigne et al., 1997; Kelso, 2013). This conception provides an alternative explanation of the patterns that are neither fully ordered nor disordered in space and time by conceptualising a given system as a "whole", as well as its respective parts and their relationships. For instance, complex social systems show consistency in the macroscopic pattern, which emerge from the interaction between their components. However, the components themselves vary according to their functions (Manoel, Basso, Corrêa, \& Tani, 2002; Weiss, 1971). Supporting evidence for these ideas was provided by Corrêa, Alegre et al. (2012) who demonstrated that opposing teams provided attacking and defensive patterns in a game of futsal. However, each of these included within-pattern variability; that is, the actions of individual players were unpredictable and irregular.

Another important aspect of this hierarchical conception is that there are no whole and parts absolute (Kelso, 2000, 2002; Ladyman, Lambert, \& Wiesner, 2013). For instance, a dyad (attacker-defender sub-system) in a game of futsal might be analysed as a whole because it is formed by the coupling of two distinctive components (an attacker and defender), as in 1 vs. 1 situations studied by Vilar, Araújo, Davids and Travassos (2012). On the other hand, dyads could be viewed as components that form another sub-system, as characterized by the 2 vs. 2 situation (Corrêa, Vilar, Davids, \& Renshaw, 2012).

Important challenges to sports scientists investigating team sports behaviour are to identify collective variables which capture the interdependence between levels of analysis of interpersonal coordination in team sports, and to understand how such measures can be recorded (Kelso, 2013). As a result, the ecological dynamic perspective has been acknowledged as a promising alternative for studying interpersonal coordination in team sports in the last few years (Araújo, Davids, Chow, \& Passos, 2009; Araújo, Davids, \& Hristovski, 2006; Davids, 2013; Vilar, Araújo, Davids, \& Button, 2012). It refers to a perspective that uses concepts and tools from dynamical systems theories, ecological psychology, and cognitive psychology to understand decision-making phenomena on an ecological scale, i.e. the scale of interactions between performers and their environment (Araújo, et al., 2006; Araújo, Ripoll \& Raab, 2009; Davids, 2013). In addition to interpersonal coordination, two other types of interaction have been used for behavioural analyses in sport contexts: intrapersonal (e.g. between segments of a movement pattern) and extrapersonal (e.g. between the individual and some aspect of the environment) (Millar, Oldham, \& Renshaw, 2013). Research has highlighted the potential of spatial measures and their temporal ratios of change (e.g. distance, angle, velocity measures) in functioning as collective variables. That is, spatiotemporal variables have enabled researchers to identify a given interaction within a system. Furthermore, research has shown that decisions are made under the influence of the specific values of such measures (see Vilar, Araújo, Davids, \& Button, 2012).

Ecological dynamic research has investigated the influential aspects and processes involved in decisionmaking behaviours in a number of team sports, including futsal (indoor soccer). Futsal is FIFA's (Federation de Football Association) official indoor football game, played between two teams of five players each (one of whom is the goalkeeper) on small court (the maximum length of 42 meters and a minimum of 25 meters, with a maximum width of 22 meters and a minimum of 15 meters), with a small ball (circumference of $62 \mathrm{~cm}$ at a minimum and 64 maximum; weighs between $400 \mathrm{~g}$ and $440 \mathrm{~g}$ ). Previous research has examined the three main 
competitive situations related to decision-making observed in the team sport of futsal: shooting (Vilar, Araújo, Davids, Correia, \& Esteves, 2012); passing (Corrêa, Vilar et al., 2012; Travassos, Araújo, Davids, Esteves, \& Fernandes, 2012; Travassos, Araújo, Davids, Vilar, Esteves, \& Vanda, 2012), and, of particular concern to the present study, players' positioning on court (Travassos, Araújo, Duarte, \& McGarry, 2012; Travassos, Araújo, Vilar, \& McGarry, 2011; Vilar, Araújo, Davids, \& Travassos, 2012).

The importance of the spatial and temporal characteristics of the players' positioning on the court has been acknowledged as a key aspect of cooperative and oppositional interpersonal coordination (Howarth, 2001). Both are closely related to the players' capacity to effectively function as a team. Indeed, the game dynamic might be viewed as a result of how players use space. For instance, in a game of futsal the ball carrier seeks to position him/herself far from his/her marking defender in order to create a gap for passing or shooting, while the marking defender attempts to do the opposite; simultaneously, the ball carrier's teammates attempt to create gaps in relation to their marking defenders in order to facilitate a pass, while defenders seek to eliminate such gaps, and the opportunities for passing (Corrêa, Alegre et al., 2012).

Recent works by Travassos et al. (2011) and Travassos, Araújo, Duarte et al. (2012) investigated the synchrony between the movement kinematics of players and the ball, as well as between players themselves, during a game situation in which the goalkeeper played as an outfield player. First, they analysed the dynamic behaviour between players, and then between them and the ball, regard to the relative phase of longitudinal and lateral displacements on the court. They found stronger relative phases in the lateral direction. Next, they analysed the positioning of the ball and teams with reference to the goal in terms of the relative phase, which included polar coordinate values (angle and radial distance). They showed that the defending team had stronger phase relations with the ball than the attacking team. They also observed that players demonstrated a greater tendency of displacement in the lateral direction than the longitudinal one.

In the present study, we aimed to extend current understanding of the influence of the goalkeeper acting as an outfield player on defensive subsystems in futsal. Most situations in futsal are characterized by the coupling of defenders and attackers as outfield players. However, it is common for a losing team's goalkeeper to play as an outfield player (or he/she is substituted by another outfield player) in the final moments of competitive games in order to provide an overload in attack. In this situation, the numerical advantage of the attacking team affords additional gaps for performing passing or shooting. For this reason, it was expected that the defending outfield players would adapt their modes of coupling by forming an additional coupling with the goalkeeper. In other words, we hypothesized that when a goalkeeper played as an outfield player, the defending outfield players would create a new pattern of interpersonal coordination by dividing their couplings between the nearest attacker and the additional player (goalkeeper). As a consequence, it was expected that we would observe: 1) an increased distance between the defender and attacker as a dyadic subsystem, although without the coupling; 2) an increased distance between the defender to the trajectory of a pass or shot; and 3), a reduced defensive area in the defending team. Thus, these three physical measures were used as collective variables which reflected the players' coordination as defensive subsystems, in response to an overload by the goalkeeper.

\section{Method}

This study was conducted within the guidelines of the American Psychological Association. The protocol was approved by the local ethics committee of the University of São Paulo.

\subsection{Participants}

Participants were comprised of 23 male amateur players $(\mathrm{M}=26.24$ years; $\mathrm{SD}=3.34$ years $)$ who took part in the final of the Futsal League of Carapicuiba/2012. This is an annual championship held in Carapicuiba-Brazil, involving 1170 players from 78 teams and seven categories

\subsection{Data Collection}

All sequences of play involving the goalkeeper $(n=65)$, and the preceding and proceeding sequences without a goalkeeper (controls) $(n=11)$ were selected from digital video footage of the aforementioned final game. Trials ranged from 0.08 to 3.48 seconds of duration. Sequences of play were recorded using a digital camera (CASSIO HS EX-FH100; frequency $=25 \mathrm{~Hz}$ ) located above and behind the short axis of a futsal court, which had dimen- 
sions of $18.0 \mathrm{~m} \times 30.0 \mathrm{~m}$. This procedure involved the collection of data on the players' movement displacement trajectories through consideration of their passing and shooting behaviours. Specifically, data were collected from: 1) the moment the ball carrier received the ball until the moment a teammate received the pass (successful passes, $n=27$ ) or a defender intercepted the intended pass to the teammate (unsuccessful passes, $n=10$ ); and 2), the moment the ball carrier received the ball until the moment the ball reached the opposing goal area through the goalkeeper's interception or due to a goal being scored (successful kicks, $n=27$ ), or when a defender intercepted the intended shot at goal (unsuccessful kicks, $n=10$ ).

\subsection{Data Analysis}

TACTO software (Fernandes, Folgado, Duarte, \& Malta, 2010) was used to capture movement displacement trajectories by following the vertical projection of each player's working point on the futsal court with a computer mouse in a slow-motion video image (frequency $=2 \mathrm{~Hz}$ ). The working point is represented as midway between the foot-stance of each player brought about by the projection on the floor of the centre-of-mass (Corrêa, Vilar et al., 2012; Passos, Araújo, Davids, Gouveia, \& Serpa, 2006). In sum, the TACTO software allowed us to obtain the $x$ and $y$ values of players' displacement trajectories at a frequency of 25 frames per second.

Following this procedure, the virtual coordinates (i.e. in pixels) were transformed into real coordinates (i.e. in metres) using a bidimensional direct linear transformation method (2D-DLT) filtered with a low pass filter (6 Hz) (Winter, 2005). This method considers the $z$ coordinates to be equal to zero, and directly correlates an object point located in the object space/plane with a corresponding image point on the image plane.

From the displacement coordinates of the players, we calculated three collective variables, each representing different measures of a team's coordination tendencies: 1) defensive area (Figure 1(A)); 2) average intra-dyad distance (Figure 1(B)); and 3), the average interception distance of the shot (Figure 1(C)).

The defensive area is the area of the quadrilateral formed by the defensive outfield players. It was obtained through the equation: $A=\frac{1}{2}\left(x_{1} y_{2}-x_{2} y_{1}+x_{2} y_{3}-x_{3} y_{2}+x_{3} y_{4}-x_{4} y_{3}+x_{4} y_{1}-x_{1} y_{4}\right)$ where $A$ refers to the calculated area; and $x_{i}$ and $y_{i}$ correspond to the position of the $i$-th player in $x$ and $y$ coordinates, respectively (Weisstein, 2013). To avoid using the area of a self-intersecting polygon, we calculated the area for all possible player combinations and selected the largest. From the area values of each frame, we then calculated the team's coordination tendency expressed in the sequence of play using $\mu=\left(\sum A_{\mathrm{i}}\right) / \mathrm{n}$, where $A$ refers to the area and $\mathrm{n}$ is the number of observations (frames). The area as a measure of a team's coordination tendency was also analysed in relation to its variability over a sequence of play by $C V=\sigma / \mu$, where $C V$ is the ratio of variability (coefficient of variation), $\sigma$ refers to the standard deviation, and $\mu$ is the arithmetic mean.

Second, the average intra-dyad distance refers to the average distance between an attacker and a marking defender (both outfield players), which formed four dyadic subsystems. We used the following equation for this purpose: $\mu=\left(\sum I D_{\mathrm{i}}\right) / 4$, where $I D$ refers to the intra-dyad distance. The intra-dyad distances were computed individually using the Pythagorean theorem, and the $x$ and $y$ coordinates from the players of each dyad. From the intra-dyad distance in each frame, we then calculated the team's average coordination tendency expressed in the sequence of play by $\mu=\left(\sum I D D_{\mathrm{i}}\right) / \mathrm{n}$, where $I D D$ refers to the intra-dyad distance, and $\mathrm{n}$ is the number of observations (frames). The average intra-dyad distance was also considered with regard to its ratio of variability over the course of the frames that composed the sequence of play. In this case, we also used $C V=\sigma / \mu$, where $C V$ is the coefficient of variation, $\sigma$ refers to the standard deviation, and $\mu$ is the arithmetic mean.

Finally, the average interception distance of the kick was the average distance between the defensive players and the kick line (imaginary line connecting the ball carrier with the middle of the goal). It was calculated using the point to line $d=\frac{\left(x_{g}-x_{c}\right)\left(y_{c}-y_{p}\right)-\left(x_{c}-x_{p}\right)\left(y_{g}-y_{c}\right)}{\sqrt{\left(x_{g}-x_{c}\right)^{2}+\left(y_{g}-y_{c}\right)^{2}}}$, where $x$ and $y$ correspond to the position in each coordinate for $g$ (middle point of the goal line), $c$ (ball carrier) and $p$ (a given defensive player) (Weisstein, 2013). From the interception distance in each frame, we then calculated a team's average coordination tendency expressed in the sequence of play by $\mu=\left(\sum I T D_{\mathrm{i}}\right) / \mathrm{n}$, where ITD refers to the interception distance and $\mathrm{n}$ is the number of observations (frames). The average intra-dyad distance was also considered with regard to its ratio of variability over the frames that composed the sequence of play. In this case, we also used $C V=\sigma / \mu$, where $C V$ 


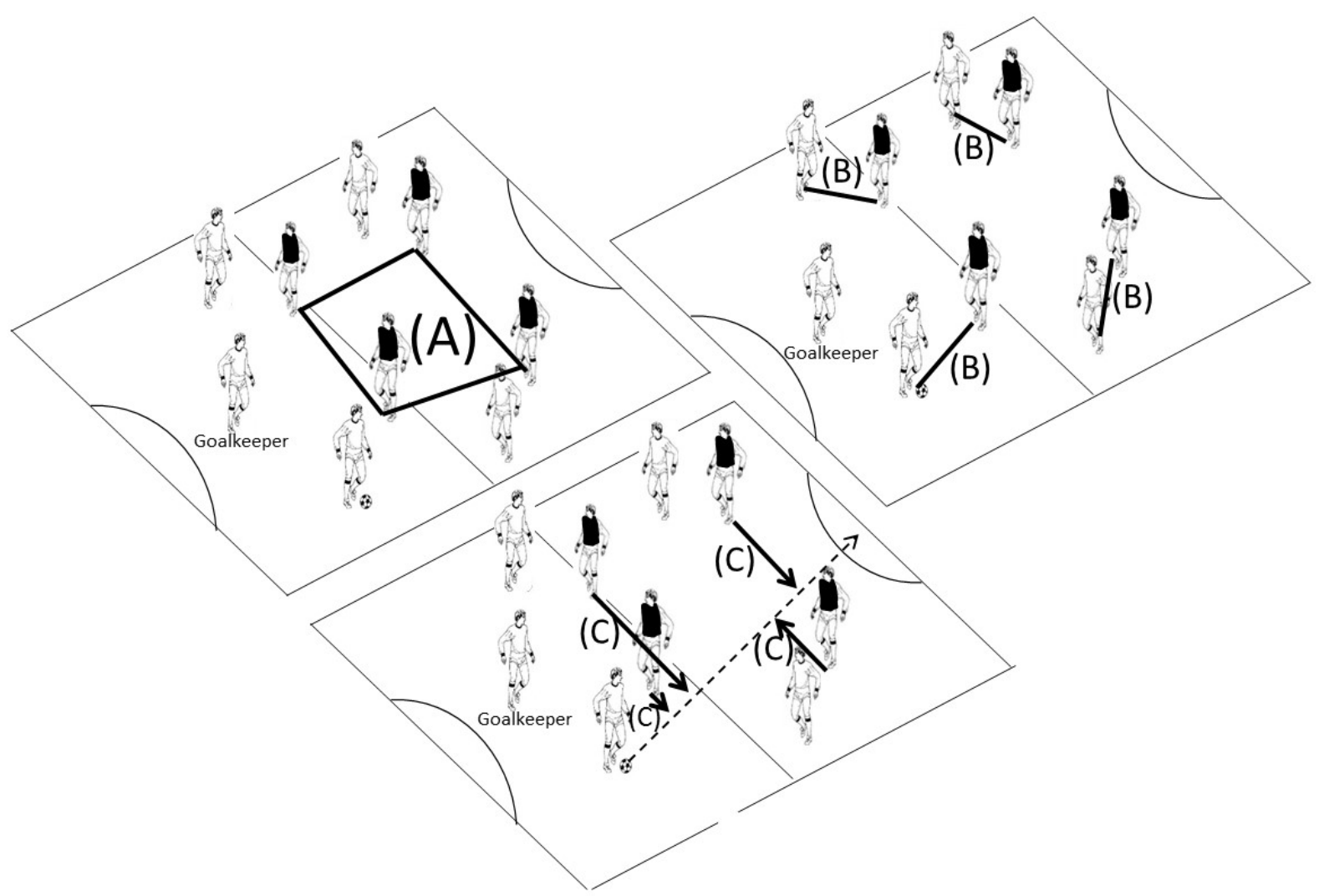

Figure 1. Illustration of the measures of interpersonal coordination tendencies: (A) Defensive area; (B) Intra-dyad distance; (C) Interception distance of the kick.

is the coefficient of variation, $\sigma$ refers to the standard deviation, and $\mu$ is the arithmetic mean.

\subsection{Statistical Procedures}

The average defensive area, average intra-dyad distance, and average interception distance of the kick were all analysed considering situations involving a goalkeeper and no goalkeeper, and the aforementioned successful and unsuccessful performance of passing and shooting (Table 1). Welch's $t$-test for unequal variances was used to compare successful passes, and the Mann-Whitney $U$ test was run to compare unsuccessful passes. The Welch's $t$-test, or the $t$-test with Welch correction, was designed to provide a valid $t$-test in the presence of unequal population variances. Instead of a pooled variance estimate, this test uses sample variances and sample sizes from each sample to compute the $t$ statistic. As such, it can also be used to evaluate differences between samples with unequal numbers of observations, due to it being conservative in this situation. The Mann-Whitney $\mathrm{U}$ test is a nonparametric test for differences between two independent samples. It is an alternative to a $t$-test when assumptions of normal distribution in the population or sample cannot be guaranteed, such as in samples of very small sizes. For all analyses, the level of significance was set at $p<0.05$, using SPSS 14 (IBM Corporation, USA).

\section{Results}

Data presented in Figure 2 show the values obtained in the goalkeeper and no-goalkeeper situations, successful and unsuccessful passing and shooting as related to the average defensive area, the average intra-dyadic distance, and the average interception distance of the kick.

Regarding the descriptive statistical analyses, Figure 2 shows a clear tendency for smaller average defensive areas to be related to unsuccessful passes in goalkeeper situations. This also seems to be the case for the variability of the defensive area. Concerning the average intra-dyadic distance, Figure 2 shows a tendency for 
Table 1. Number of successful and unsuccessful passes and kicks for goalkeeper and no-goalkeeper situations.

\begin{tabular}{ccc}
\hline Outcome & Goalkeeper & No Goalkeeper \\
\hline Successful passes & 51 & 7 \\
Unsuccessful passes & 3 & 3 \\
Successful kicks & 7 & 0 \\
Unsuccessful kicks & 4 & 1 \\
\hline
\end{tabular}
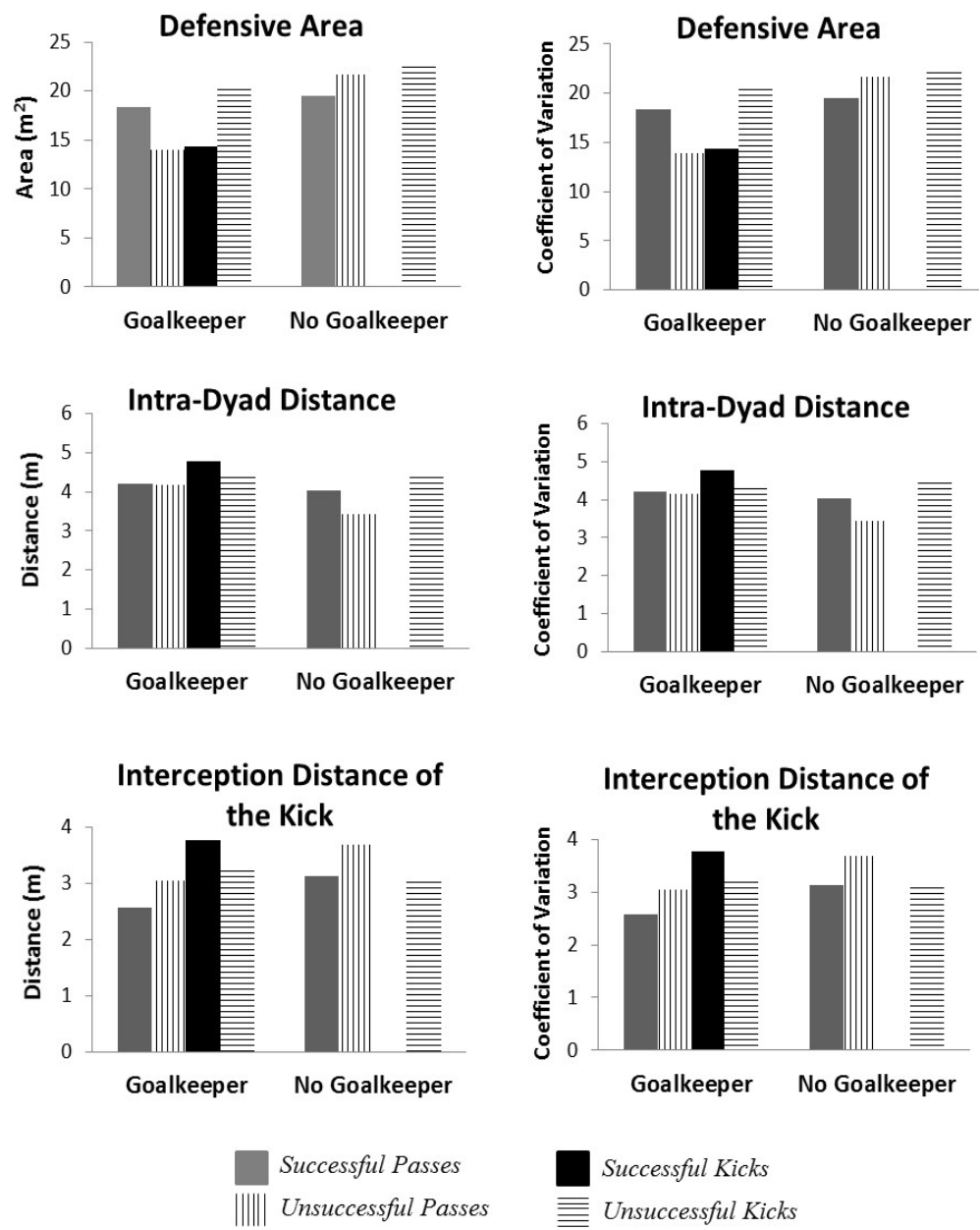

Figure 2. Values of the defensive area, average intra-dyadic distance, and average interception distance of the kick, for successful and unsuccessful passing and kicking in goalkeeper and no goalkeeper situations.

different values for goalkeeper and no-goalkeeper situations both in terms of the magnitude and variability of unsuccessful passes. With respect to the average interception distance of the kick, it seems that the goalkeeper situation involves the smallest values for successful and unsuccessful passes.

Interestingly, successful shots only occurred when goalkeepers were involved in play. Figure 2 shows that they occurred in cases with the following values: average defensive area $=14.38 \mathrm{~m}^{2}$; average interception distance to the kick $=3.77 \mathrm{~m}$; and average intra-dyad distance $=4.77 \mathrm{~m}$. Unsuccessful shots occurred in cases with the following values: average defensive area $=22.47 \mathrm{~m}^{2}$; average interception distance to the kick $=3.11 \mathrm{~m}$; and average intra-dyad distance $=4.47 \mathrm{~m}$.

In terms of magnitude the Welch's $t$-test for unequal variances, the inferential analyses did not reveal a difference for any measure of successful passes: defensive area $(t=0.70, p=0.79)$; intra-dyad distance $(t=0.14, p$ $=0.71)$; and interception distance of the kick $(t=2.96, p=0.14)$. For the unsuccessful passes, the 
Mann-Whitney $\mathrm{U}$ test revealed a difference in the defensive area $(\mathrm{Z}=-1.96, p=0.05)$. The other results were: intra-dyad distance $(\mathrm{Z}=-0.22, p=0.82)$; and interception distance of the kick $(\mathrm{Z}=-1.09, p=0.27)$.

Similar results were found concerning variability. Welch's $t$-test for unequal variances did not reveal a difference for any measure of successful passes: defensive area $(t=1.04, p=0.34)$; intra-dyad distance $(t=0.42, p$ $=0.54)$; or interception distance of the kick $(t=0.26, p=0.63)$. But the Mann-Whitney $\mathrm{U}$ test did reveal a difference for the unsuccessful passes in the defensive area $(Z=-1.96, p=0.05)$. Other results included: intra-dyad distance $(\mathrm{Z}=-1.09, p=0.26)$; and interception distance of the kick $(\mathrm{Z}=-1.09, p=0.27)$.

\section{Discussion}

The aim of this study was to investigate how the goalkeeper as an outfield player affected players' behaviours in defensive subsystems during game of futsal. The results produced two main findings. First, they showed that in situations involving a goalkeeper, players as a team reduced the defensive area and its variability. This was a more effective strategy because it was associated with unsuccessful passes. Second, the results indicated that using the goalkeeper as an outfield player was an effective strategy for attacking in terms of kick actions.

With regards to the first result, it seems that the goalkeeper involvement functioned as a control parameter by constraining the formation of new stable patterns of coordination between defensive players in opposing teams (McGarry, 2009; McGarry \& Franks, 1996; McGarry et al., 2002). This new pattern was characterized by a specific form of positioning known as a "zone defence.” As stated by Travassos et al. (2011) and Travassos, Araújo, Duarte et al. (2012), defending players utilise a zone defence in the goalkeeper situation in order to deal with the numerical advantage of the attacking team. However, this new pattern of coordination did not limit goal-scoring opportunities by reducing space. Interestingly, this actually seems to be because successful shots only occurred during the goalkeeper situations, which means using the goalkeeper as an outfield player was an effective attacking strategy in terms of attacks on goal. Thus, we suggest that the new pattern of coordination presented by the defenders during the goalkeeper situations showed only a partial functional character, since it only helped in intercepting passes.

Since the perceptual attunement to the dynamic flux of information related to interpersonal coordination (attention to the players' displacement characteristics) is closely related to the effectiveness of decision-making behaviours (Araújo et al., 2006; Fajen, Riley, \& Turvey, 2009), it is possible that defenders were not able to perceive the real risks (i.e. pass and shot) afforded by involvement of goalkeepers, nor were they able to decide on the most appropriate action when faced with this overload. Perhaps defender players were not able to perceive the need to break the coupling between themselves and their immediate opponents, or between themselves and a potential shot trajectory, when interacting within the diminished area of play.

In fact, the literature has highlighted the importance of the defenders' attunement to the shot line. For instance, Vilar, Araújo, Davids, Correia et al. (2012) showed that values of distance from the defenders and goalkeeper to shot interception points were significantly lower when they successfully intercepted the ball. Our hypotheses were contrary to this finding because we did not study a common 4 vs. 4 situation, i.e. involving only outfield players. We expected that the distances between defenders and attackers as a dyadic subsystem, and between defenders to the trajectory of a shot, would increase because the outfield defenders would have to form a new coupling involving the attackers of their dyads and the additional player.

Finally, the results could also be considered from an adaptation viewpoint (Corrêa, Alegre et al., 2012). Adaptation occurs when changes in the environment perturb the system, challenging its stability and causing uncertainties (Conrad, 1983; Ugrinowitsch, Santos-Naves, Carbinatto, Benda, \& Tani, 2011). Thus, using the goalkeeper as an outfield player might have acted as a perturbation because it broke the stability of the defensive area. According to Corrêa, Alegre et al. (2012), an adaptation of a defensive team could occur in two basic ways according to the type of perturbation. For instance, a small perturbation would require the team to adapt itself by altering only one parameter (e.g. area) in its defensive pattern. On the other hand, a large perturbation would demand the team adapt by reorganizing the structure of its overall defensive pattern, e.g. by altering the intra-dyad distance, interception distance, and defensive area. In any case, whatever the modification, it should be functional enough to be considered an adaptation. Based on this idea, one might have expected that the defensive team would have changed its defensive pattern in relation to all variables (as hypothesized) rather than solely changing the area. 


\section{Conclusion}

In conclusion, our results showed that in order to deal with goalkeeper overload situations, players as a team diminished the defensive area and used it less variably. This seemed to be an effective strategy because it was associated with unsuccessful passes by the attacking team. However, this strategy was not capable of reducing the number of shooting actions by the attacking team. Practically, these findings suggest that attacking teams in futsal must make quick transitions to create overloads when the goalkeeper moves into the field, otherwise defending teams will create a defensive zone to restrict attacking space.

\section{References}

Araújo, D., Davids, K., Chow, J., \& Passos, P. (2009). The Development of Decision Making Skill in Sport: An Ecological Dynamics Perspective. In D. Araújo, H. Ripoll, \& M. Raab (Eds.), Perspectives on Cognition and Action in Sport (pp. 157-170). New York: NOVA Science Publishers.

Araújo, D., Davids, K., \& Hristovski, R. (2006). The Ecological Dynamics of Decision Making in Sport. Psychology of Sport and Exercise, 7, 653-676. http://dx.doi.org/10.1016/j.psychsport.2006.07.002

Araújo, D., Ripoll, H., \& Raab, M. (2009). Perspectives on Cognition and Action in Sport. New York: NOVA Science Publishers.

Conrad, M. (1983). Adaptability: The Significance of Variability from Molecule to Ecosystem. New York: Plenum Press.

Corrêa, U.C., Alegre, F., Freudenheim, A. M., Santos, S., \& Tani, G. (2012). The Game of Futsal as an Adaptive Process. Nonlinear Dynamics, Psychology, and Life Sciences, 16, 185-204.

Corrêa, U. C., Vilar, L., Davids, K., \& Renshaw, I. (2012). Informational Constraints on the Emergence of Passing Direction in the Team Sport of Futsal. European Journal of Sport Science, 6, 1-8. http://dx.doi.org/10.1080/17461391.2012.730063

Davids, K. (2013). Ecological Dynamics in Analysis of Performance in Team Sport. In N. Balagué, C. Torrents, A. Vilanova, J. Cadefau, R. Tarragó, \& E. Tsolakidis (Eds.), Book of Abstracts: 18th Annual Congress of the European College of Sport Science (p. 80). 26th-29th June 2013, Barcelona.

Davids, K., Araújo, D., \& Shuttleworth, R. (2005). Applications of Dynamical Systems Theory to Football. In J. Cabri, T. Reilly, \& D. Araújo (Eds.), Science and Football V (pp. 556-569). London: Routledge.

Fajen, B. R., Riley, M. A., \& Turvey, M. T. (2009). Information, Affordances, and the Control of Action in Sport. International Journal of Sport Psychology, 40, 79-107.

Fernandes, O., Folgado, H., Duarte, R., \& Malta, P. (2010). Validation of the Tool for Applied and Contextual Time-Series Observation. International Journal of Sport Psychology, 41, 63-64.

Garganta, J., \& Cunha e Silva, P. (2000). O jogo de futebol: Entre o caos e a regra. Horizonte, 91, 5-8.

Gréhaigne, J. F., Bouthier, D., \& David, B. (1997). Dynamic-System Analysis of Opponent Relationships in Collective Actions in Soccer. Journal of Sports Sciences, 15, 137-149. http://dx.doi.org/10.1080/026404197367416

Howarth, K. (2001). Space, the Final Frontier! Space as a Key Concept in the Teaching of Invasion Games. Teaching Elementary Physical Education, 12, 8-11.

Kelso, J. A. S. (2000). Principles of Dynamic Pattern Formation and Change for a Science of Human Behavior. In L. R. Bergman, R. B. Cairns, L.-G. Nilsson, \& L. Nystedt (Eds.), Developmental Science and the Holistic Approach (pp. 63-83). Hillsdale, NJ: Lawrence Erlbaum Associates.

Kelso, J. A. S. (2002). The Complementary Nature of Coordination Dynamics: Self-Organization and Agency. Nonlinear Phenomena in Complex Systems, 5, 364-371.

Kelso, J. A. S. (2013). Whither Sport Science? The Challenge of Understanding Living Movement. In N. Balagué, C. Torrents, A. Vilanova, J. Cadefau, R. Tarragó, \& E. Tsolakidis (Eds.), Book of Abstracts: 18th Annual Congress of the European College of Sport Science (p. 352). 26-29 June 2013, Barcelona.

Ladyman, J., Lambert, J., \& Wiesner, K. (2013). What Is a Complex System? European Journal of Philosophy of Science, 3 , 33-67. http://dx.doi.org/10.1007/s13194-012-0056-8

Manoel, E. J., Basso, L., Corrêa, U. C., \& Tani, G. (2002). Modularity and Hierarchical Organization of Action Programs in Human Acquisition of Graphic Skills. Neuroscience Letters, 335, 83-86.

http://dx.doi.org/10.1016/S0304-3940(02)01102-3

Marsh, K. L., Richardson, M. J., Baron, R. M., \& Schmidt, R. C. (2006). Contrasting Approaches to Perceiving and Acting with Others. Ecological Psychology, 18, 1-38. http://dx.doi.org/10.1207/s15326969eco1801_1

McGarry, T. (2009). Applied and Theoretical Perspectives of Performance Analysis in Sport: Scientific Issues and Challenges. International Journal of Performance Analyses in Sport, 9, 128-140. 
McGarry, T., Anderson, D. I., Wallace, S. A., Hughes, M., \& Franks, I. M. (2002). Sport Competition as a Dynamical Self-Organizing System. Journal of Sports Sciences, 20, 771-781. http://dx.doi.org/10.1080/026404102320675620

McGarry, T., \& Franks, I. M. (1996). In Search of Invariant Athletic Behaviour in Competitive Sport Systems: An Example from Championship Squash Match-Play. Journal of Sports Sciences, 14, 445-456. http://dx.doi.org/10.1080/02640419608727730

Millar, S. K., Oldham, A. R., \& Renshaw, I. (2013). Interpersonal, Intrapersonal, Extrapersonal? Qualitatively Investigating Coordinative Couplings between Rowers in Olympic Sculling. Nonlinear Dynamics Psychology, and Life Science, 17, 425-443.

Passos, P., Araújo, D., Davids, K., Gouveia, L., Milho, J., \& Serpa, S. (2009). Interpersonal Coordination Tendencies, Decision-Making and Information Governing Dynamics in Rugby Union. In D. Araújo, H. Ripoll, \& M. Raab (Eds.), Perspectives on Cognition and Action in Sport (pp. 27-42). New York: NOVA Science Publishers.

Passos, P., Araújo, D., Davids, K., Gouveia, L., \& Serpa, S. (2006). Interpersonal Dynamics in Sport: The Role of Artificial Neural Networks and Three-Dimensional Analysis. Behavior and Research Methods, 38, 683-691. http://dx.doi.org/10.3758/BF03193901

Passos, P., Araújo, D., Davids, K., Gouveia, L., Serpa, S., Milho, J., \& Fonseca, S. (2009). Interpersonal Pattern Dynamics and Adaptive Behavior in Multiagent Neurobiological Systems: Conceptual Model and Data. Journal of Motor Behavior, 41, 445-459. http://dx.doi.org/10.3200/35-08-061

Schmidt, R. C., O’Brien, B., \& Sysko, R. (1999). Self-Organization of Between-Persons Cooperative Tasks and Possible Applications to Sport. International Journal of Sport Psychology, 30, 558-579.

Travassos, B., Araújo, D., Davids, K., Esteves, P. T., \& Fernandes. O. (2012). Improving Passing Actions in Team Sports by Developing Interpersonal Interactions between Players. International Journal of Sports Science \& Coaching, 7, 677-688. http://dx.doi.org/10.1260/1747-9541.7.4.677

Travassos, B., Araújo, D., Davids, K., Vilar, L., Esteves, P., \& Vanda, C. (2012). Informational Constraints Shape Emergent Functional Behaviours during Performance of Interceptive Actions in Team Sports. Psychology of Sport and Exercise, 13, 216-223. http://dx.doi.org/10.1016/j.psychsport.2011.11.009

Travassos, B., Araújo, D., Duarte, R., \& McGarry, T. (2012). Spatiotemporal Coordination Behaviors in Futsal (Indoor Football) Are Guided by Informational Game Constraints. Human Movement Science, 31, 932-945. http://dx.doi.org/10.1016/j.humov.2011.10.004

Travassos, B., Araújo, D., Vilar, L., \& McGarry, T. (2011). Interpersonal Coordination and Ball Dynamics in Futsal (Indoor Football). Human Movement Science, 30, 1245-1259. http://dx.doi.org/10.1016/j.humov.2011.04.003

Ugrinowitsch, H., Santos-Naves, S. P., Carbinatto, M. V., Benda, R. N., \& Tani, G. (2011). Motor Skill Adaptation Depends on the Level of Learning. International Journal of Human and Social Sciences, 6, 177-181.

Vilar, L., Araújo, D., Davids, K., \& Button, C. (2012). The Role of Ecological Dynamics in Analysing Performance in Team Sports. Sports Medicine, 42, 1-10. http://dx.doi.org/10.2165/11596520-000000000-00000

Vilar, L., Araújo, D., Davids, K., Correia, V., \& Esteves, P. T. (2012). Spatial-Temporal Constraints on Decision-Making during Shooting Performance in the Team Sport of Futsal. Journal of Sports Sciences, 31, 1-7.

Vilar, L., Araújo, D., Davids, K., \& Travassos, B. (2012). Constraints on Competitive Performance of Attacker-Defender Dyads in Team Sports. Journal of Sports Science, 30, 459-469. http://dx.doi.org/10.1080/02640414.2011.627942

Weiss, P. A. (1971). The Basic Concept of Hierarchic Systems. In P. A. Weiss (Ed.), Hierarchically Organized Systems in Theory and Practice (pp. 1-44). New York: Hafner.

Weisstein, E. W. (2013). Point-Line Distance-2-Dimensional. Wolfram MathWorld. http://mathworld.wolfram.com/Point-LineDistance2-Dimensional.html

Winter, D. A. (2005). Biomechanics and Motor Control of Human Movement (3rd ed.). New York: John Wiley \& Sons, Inc. 